\title{
Areal investigation of drifting snow on Tsugaru Plain, Japan
}

\author{
Masao Higashiura, Takeshi Sato, Atsushi Sato, Tadashi Kimura, \\ Shinjo Branch of Snow and Ice Studies, National Research Institute for Earth Science and Disaster Prevention (NIED), \\ Shinjo, Yamagata 996, Japan
}

\author{
Masayuki Maki, Sento Nakai, Hideomi Nakamura and Tsuruhei Yagi \\ Atmospheric and Hydrospheric Science Division, NIED, Tsukuba, Ibaraki 305, Japan
}

\begin{abstract}
This research investigates mechanisms of drifting snow accumulation, and of strong wind associated with snow clouds (developed cumulus). Detailed structure of snow drifting close to the ground was observed at several sites by use of snow particle counters (SPC), visibility meters and other meteorological instruments, simultaneously with observations of wind structure in the lower atmosphere using Doppler radar and radiosonde. Areal distributions of drifting snow were also observed as a function of time. Primary results include the following. (1) The intensity of drifting snow was found to have a strong correlation with fetch distance. Of obstacles to windward of the observation point, a river interfered with drifting snow more effectively than did a hamlet. (2) The areal distribution of drifting snow is explained fully. (3) Visibility, reflectivity and wind velocity at ground level are strongly related to drifting snow patterns.
\end{abstract}

\section{INTRODUCTION}

Recently in Japan, with rapid progress of motorization, large-size, high-speed and long-distance automobile transportation has come into wide use in snowy regions. People who have no experience of driving in snow can readily find themselves in snowy regions on the extensive highway networks. However, even well-developed traffic systems are quickly impaired by winter weather. Traffic may be interrupted by drifting snow in many places due to poor visibility and rapidly formed drifts. Such snow disasters have a great influence on both social activity and human lives.

Previous studies on drifting snow have been confined to a one-dimensional treatment at a single point. It would be preferable to investigate the phenomena of drifting snow from two- or three-dimensional viewpoints (Shitara, 1979; Takeuchi, 1980; Decker and Brown, 1983; Higashiura, 1990).

\section{RESEARCH PLAN}

A seven-year project was started in the 1986 fiscal year as a NIED joint research study, to clarify mechanisms of drifting snow, accumulation, and strong winds associated with snow clouds (developed cumulus). We sought also to develop prediction technology for preventing disasters due to drifting snow. Observations were based on the Tsugaru Plain in Aomori Prefecture, Japan, (Fig.1) where heavy-drifting snow occurs every winter. Detailed structure of drifting snow near the ground was observed at several sites by use of snow particle counters (SPC), visibility meters and other meteorological instruments.

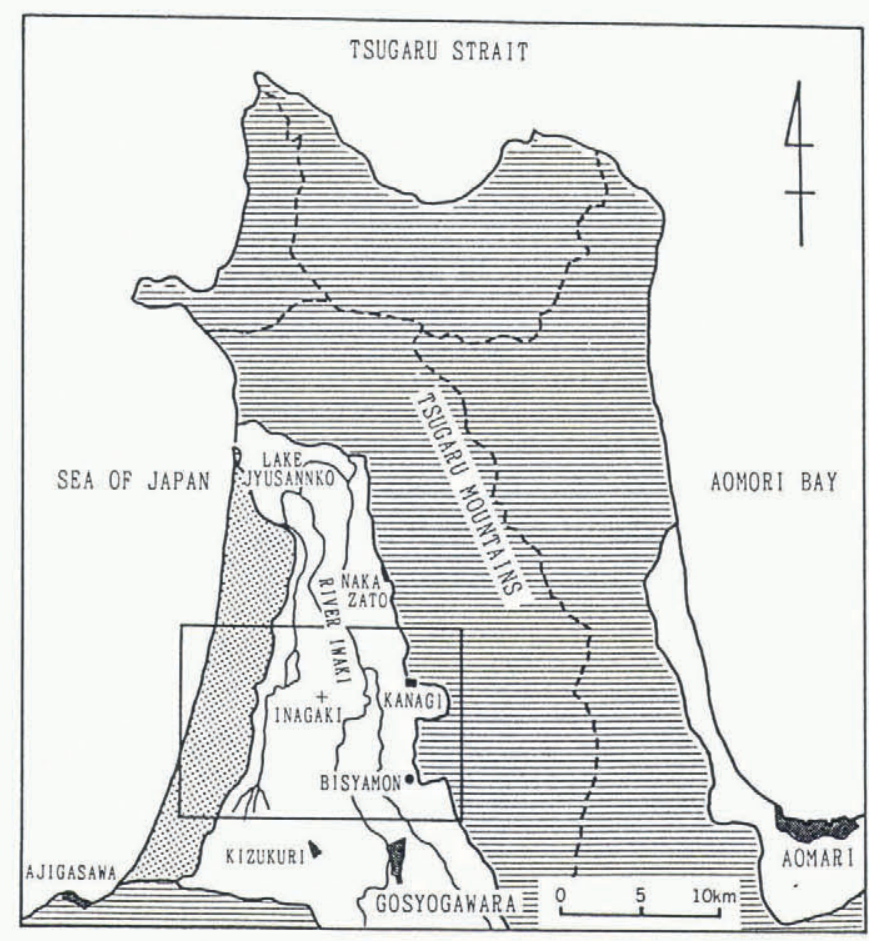

Fig. 1. Tsugaru Plain and the observation area (rectangle). 


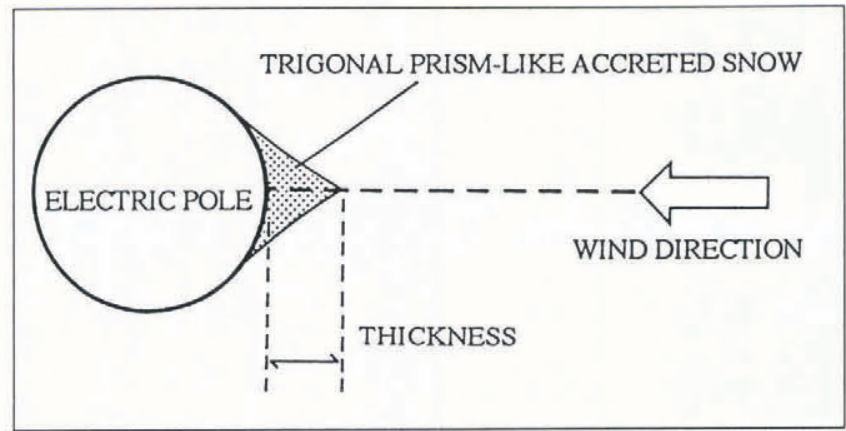

Fig. 2. Diagram of accreted snow on an electric pole.

Simultaneously, observations of strong wind structure in the lower atmosphere were made with Doppler radar and radiosonde, and areal distributions of drifting snow were also concurrently observed.

\section{RESULTS}

\section{Drift-snow flux on Tsugaru Plain}

\section{Areal investigation of drifting-snow phenomena}

The thickness and the direction of trigonal prism-like accretions of wind-blown snow on electric power poles are thought to be indices of the intensity and direction of drifting snow (Fig. 2). Though icing, which causes damage to power transmission lines, aircraft and ships, has been the subject of much research into causes and countermeasures, snow accretion has been studied in less detail, because damage from this cause is less serious and accreted snow is easily stripped away (Fujino and others, 1977; Takeuchi, 1978; Higashiura and Sato, 1988).

On Tsugaru Plain, during a period of drifting snow from 19 to 21 January 1987, snow accreted on the northwest faces of the electric poles (Fig. 3). On the morning of 22 January, after the drifting stopped, observations began at $0925 \mathrm{~h}$ and continued until $1115 \mathrm{~h}$. Data on accreted snow on poles were collected from a large area of about $100 \mathrm{~km}^{2}$ (Fig. 1).

\section{(1) Direction and thickness of accreted snow}

Data obtained from identical electric poles of $30 \mathrm{~cm}$ diameter at nine observation points appear in Figure 4. Thickness of accreted snow was measured at a height of $2.5 \mathrm{~m}$ on each pole. The accreted snow was vertically symmetric and decreased in thickness gradually from the lower to the upper part of the pole. In Figure 4, the direction of the accreted snow is indicated by arrows, with the length of the arrow proportional to the thickness of snow accretion (between 4.5 and $11.0 \mathrm{~cm}$ ). This indicates the relative magnitude of drift-snow flux, which was estimated from areal distribution of accretion with a longer fetch distance.

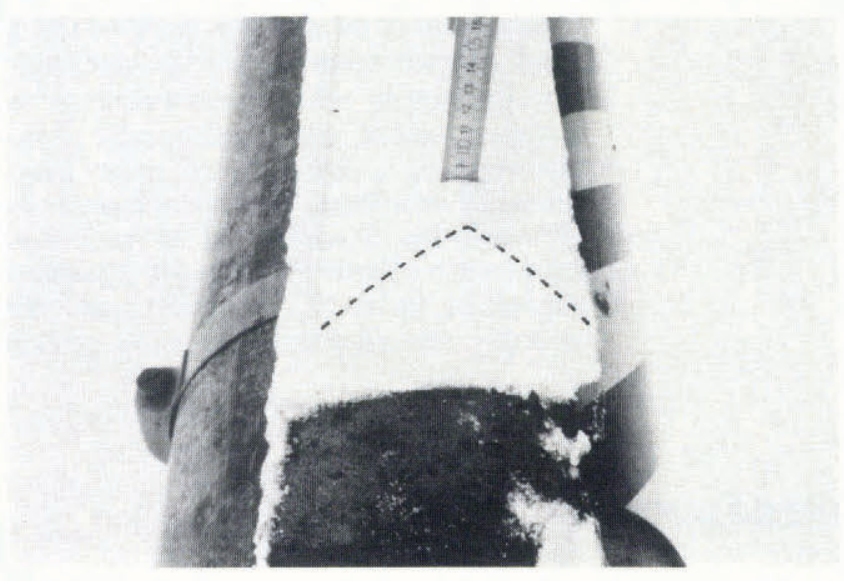

Fig. 3. Measurement of the trigonal prism-like snow accretion on an electric concrete power pole (22 January 1987). Scale shows wind direction and thickness of accreted snow.

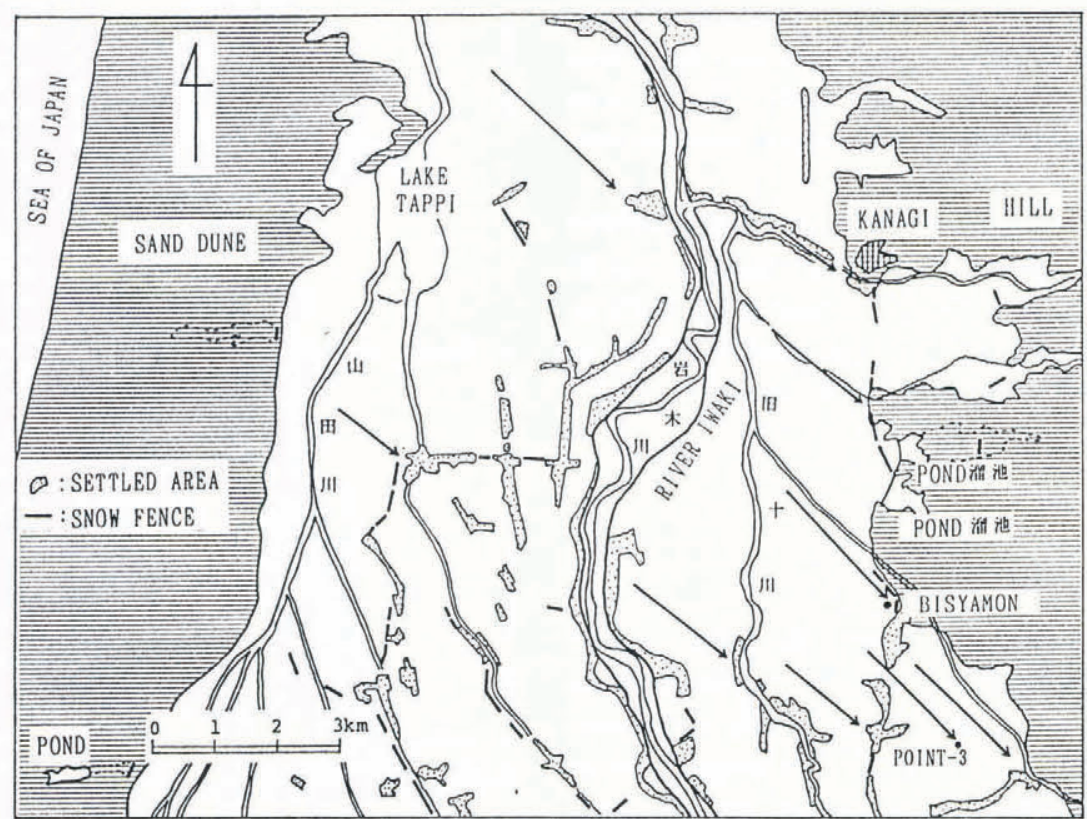

Fig. 4. Directions and intensities of drifting snow on Tsugaru Plain. Length of the arrows is proportional to thickness of the snow accretion on electric poles. The head of the arrow shows the observation point. 


\section{(2) Fetch distance and accreted snow thickness}

From observed data, aerial photographs and topographic maps, the relationship between thickness of accretion on the pole and fetch distance of drifting snow (Fig. 5) was determined. Obstacles located to windward of the observation points were classified as two types, a hamlet (solid symbol and line A in Fig. 5) and a river (open symbol and line B).

In the case of analyzing observation point 3 in Figure 4 , windward obstacles for drifting snow included both hamlet and river. If an obstacle is considered to be a hamlet (plot R in Fig. 5), the thickness of accreted snow is larger than line $\mathrm{A}$, which means that partial absence of a hamlet reduces the interference for the snow transportation. On the contrary, if an obstacle is considered to be a river (plot $\mathrm{R}^{\prime}$ in Fig. 5), the thickness lies below the line $B$, showing that the interference effect of the partial hamlet is added to the effect of the river. As a result, two types of curved lines shown in Figure 5 can be considered as valid.

\section{Distribution of drift-snow flux and Doppler radar reflectivity factor}

Ten cyclone-type drift collectors were set at a height of $1 \mathrm{~m}$ above the surface of the snow in a $100 \mathrm{~km}^{2}$ area of Tsugaru Plain (Fig. 4). During the observation period of snow-drift flux (approximately $24 \mathrm{~h}$ from 28 to 29 January 1989) the efficiency of the collector was considered, and the sublimation of collected snow was corrected by the method developed by Sato (1990) . Values of drift-snow flux were plotted on the map. The distribution of the mean reflectivity factor of the Doppler radar was obtained from scanning data recorded every $10 \mathrm{~min}$, set with an elevation angle of $0.6^{\circ}$ (Maki and others, 1989).

No systematic distribution was found for the mean

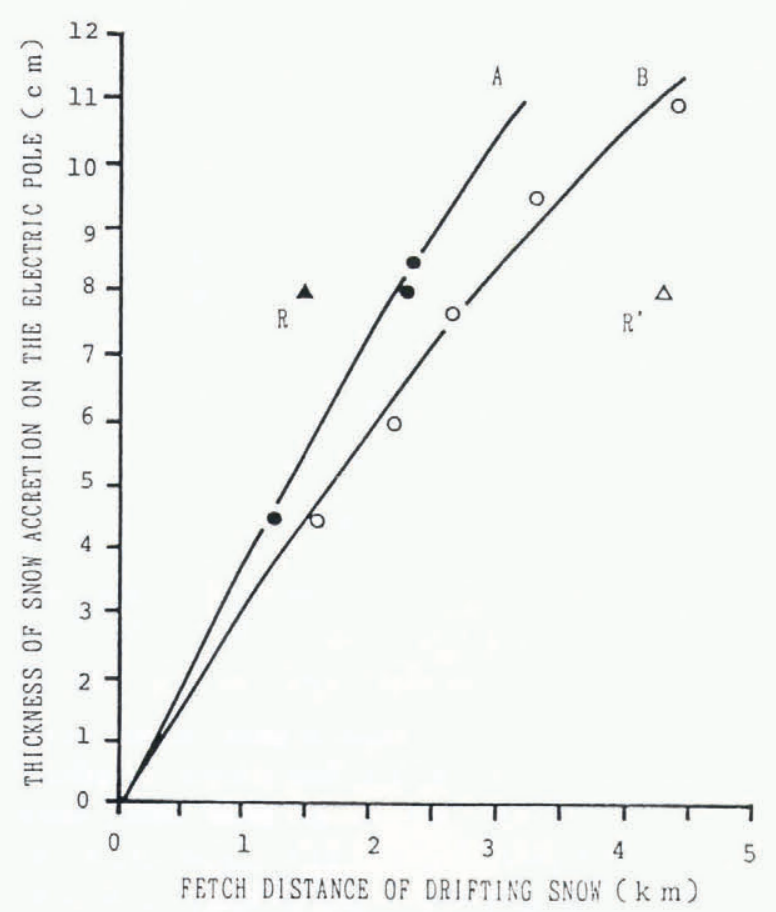

Fig. 5. Relation between thickness of snow accretion on electric poles and fetch distance of drifting snow. $\bigcirc$, pole located leeward of a river; $\bullet$, located leeward of a hamlet. reflectivity factor, showing that snow fell relatively uniformly in the test area. Relationships similar to those in the previous section between drift-snow flux and fetch distance were determined, as well as the relationship between drift-snow flux and types of windward obstacles.

By comparing the three observation points whose windward obstacles are rivers with fetch distances of $2 \mathrm{~km}$, it was found that drift snow flux increased with increasing distance from the seashore.

\section{Characteristics of the distribution of drifting snow on Tsugaru Plain (1989-91)}

The cyclone-type drift collectors were distributed at the same places as the electric poles described, $1 \mathrm{~m}$ above the snow surface, to measure areal distributions of drifting snow precisely. In the 1989 observations, the collectors were oriented to northwest. In the following year, collectors equipped with wind vanes were used (Fig. 6), and the amount of snow drifting was measured from the beginning to the end of the period of drift between 20 and $36 \mathrm{~h}$. Eight measurement sets were conducted during observation periods at the end of January 1989, 1990 and 1991 (Table 1).

It may be seen from the observations that a period with strong drifting snow occurred in 1989. In 1990, two periods of very strong drifting snow, and one period of strong drifting snow occurred. In 1991, one period of weak drifting snow and three snowfalls were observed. In all cases, the relationship was established between the weight of snow collected and fetch distances (Fig. 6)

Observations from 1989 show that the interference effect of a river for drifting snow is greater than that of the hamlet, as was the case with accreted snow on the electric poles in 1987. In 1990, observations during a period of very strong drifting snow showed that interference effect of the river (windward obstacle) was less than that of the hamlet. However, observations during strong drifting snow show that the interference effect of the river is actually greater than that of the hamlet. The 1991 observations showed that in the case of weak drifting snow, the interference effect of the river is greater than

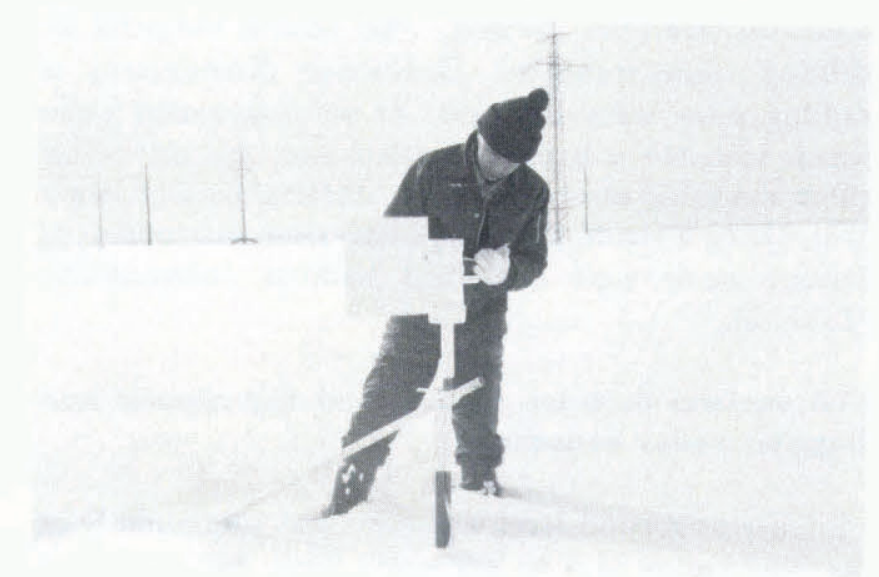

Fig. 6. Cyclone-type drift collector equipped with wind vane. 
Higashiura and others: Drifting snow on Tsugaru Plain

Table 1. Meteorological results when drifting snow was recorded by cyclone-type drift collectors at Tsugaru Plain

\begin{tabular}{|c|c|c|c|c|c|c|}
\hline \multirow[t]{2}{*}{ Year } & January & Period & \multirow{2}{*}{ Phenomena } & Mean temperature & Mean wind velocity & \multirow[t]{2}{*}{ Wind direction } \\
\hline & day & hours & & ${ }^{\circ} \mathrm{C}$ & $\mathrm{ms}^{-1}$ & \\
\hline 1989 & $28-29$ & 24 & $\begin{array}{l}\text { Strong drifting } \\
\text { snow }\end{array}$ & -4.5 to -5.0 & $10-11$ & NNW \\
\hline \multirow[t]{3}{*}{1990} & $25-26$ & 33 & $\begin{array}{l}\text { Very strong } \\
\text { drifting snow }\end{array}$ & -8.6 & 9.8 & W-WNW \\
\hline & $26-27$ & 27 & $\begin{array}{l}\text { Very strong } \\
\text { drifting snow }\end{array}$ & -7.1 & 7.4 & WSW \\
\hline & $27-28$ & 23 & $\begin{array}{l}\text { Strong drifting } \\
\text { snow }\end{array}$ & -5.8 & 7.6 & WNW \\
\hline \multirow[t]{4}{*}{1991} & $26-28$ & 36.5 & Snowfall & -0.3 & 4.6 & W-WNW \\
\hline & $28-29$ & 29.5 & Snowfall & -3.5 & 2.0 & NNW \\
\hline & $29-30$ & 19.5 & Snowfall & -2.3 & 2.4 & NW-NNW \\
\hline & $30-31$ & 24 & $\begin{array}{l}\text { Weak drifting } \\
\text { snow }\end{array}$ & 0.8 & 2.0 & W-WNW \\
\hline
\end{tabular}

that of the hamlet. In the case of snowfalls, no interference effects of river and hamlet due to fetch distance were observed.

In the 1987 and 1989 observations, the river and the hamlet are considered as windward obstacles, with interference effect of the river larger than that of the hamlet. But in 1990 the case of very strong drifting snow, reverse results were obtained.

The reason for the reversal was examined with reference to atmospheric conditions in the observation period. In this case, air temperatures were very low $\left(-7.1^{\circ} \mathrm{C}\right.$ to $\left.-8.6^{\circ} \mathrm{C}\right)$, wind velocities were very strong $\left(7.4 \mathrm{~m} \mathrm{~s}^{-1}\right.$ to $\left.9.8 \mathrm{~m} \mathrm{~s}^{-1}\right)$, with considerable snow deposited on the ground on those days. The smaller rivers covered with lots of drifting snow stagnated, froze and stopped flowing, becoming apparently insignificant obstacles for drifting snow. However, in case of very strong drifting snow, the sand dunes covered with forests to the northwest of Tsugaru Plain and the Iwaki River, which remained free from freezing, were serious obstacles for drifting snow transport. Distinctive distributions of drifting snow were analyzed. At an observation point which included a hamlet to windward, the interfering effect of drifting snow to the fetch distance became larger (Fig. 7). As a result, the eight observation phenomena of drifting snow were explained without contradiction (Table 2).

\section{Comparison between visibility at the ground and Doppler radar sounding}

Visibility at ground level was measured continuously at the observation site in Bisyamon from $0000 \mathrm{~h}$ on 28 January to $1200 \mathrm{~h}$ on 29 January 1989 . During this period, simultaneous sounding by the Doppler radar was also conducted (Maki and others, 1989) and radiosondes were released every three hours at the Doppler radar site (Fig. 8). The results are shown in Figure 9, where the reflectivity factor and Doppler velocity are values from above the Bisyamon site, derived from raw data obtained every $10 \mathrm{~min}$. The reflectivity factor is related to the

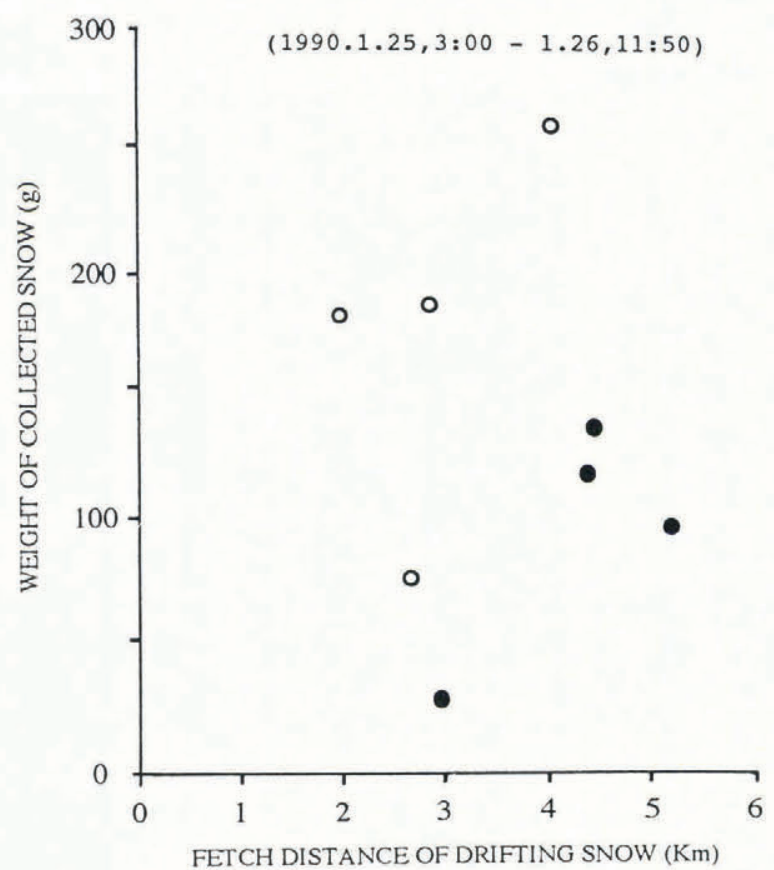

Fig. 7. Relation between weight of snow collected by the cyclone-type drift collector and fetch distance. Windward obstacles are a sand dune and the Iwaki River, which interfere with drift snow transport. Closed circles (•) represent observation sites where a hamlet is included within the fetch area. Open circles (O) represent observation sites where no hamlets are present within the fetch area. 
Phenomena

Temperature

${ }^{\circ} \mathrm{C}$
Wind velocity

$\mathrm{ms}^{-1}$
Very strong drifting snow $<-7.0$

$$
-4.0 \text { to }-7.0
$$$$
>-4.0
$$

Weak drifting snow

Snowfall

$$
-
$$

$\begin{array}{lcc}\text { Strong drifting snow } & -4.0 \text { to }-7.0 & 5-7 \\ \text { Weak drifting snow } & >-4.0 & 3-5 \\ \text { Snowfall } & - & <3\end{array}$

Obstacles and fetch distance

In case of freezing of smaller rivers, if the sand dune and the Iwaki River are considered as obstacles, phenomena are explained without contradiction
Interference effect of windward obstacles River $>$ Hamlet

The same as above

Differences of drifting-snow fluxes based on fetch distance from windward obstacles are not clear

quantity of snowflakes or snow crystals in the atmosphere. The Doppler velocity shows the wind velocity in the direction from the Doppler radar site to the Bisyamon observation site.

During the occurrence of drifting snow, especially when the Doppler reflectivity factor is larger than $20 \mathrm{dBZ}$ or Doppler velocity exceeds $14 \mathrm{~m} \mathrm{~s}^{-1}$ at the lowest measurement height $(250 \mathrm{~m})$, visibility at the ground is found to be under $100 \mathrm{~m}$. These criteria can be used to predict the location and intensity of drifting snow with the Doppler radar.

From the observational results of January 1990, a similar relationship was obtained at three observation sites, including that at Bisyamon.

\section{CONCLUDING REMARKS}

Areal distribution of drifting snow on Tsugaru Plain, observed by accreted snow on poles and cyclone-type drift collectors, has the following features: (1) the intensity of drifting snow has a strong correlation with its fetch distance; and (2) the river usually interferes with drifting snow more effectively than does the hamlet; (3) however, in cases of low air temperature and high wind velocity, the smaller rivers are ineffective as obstacles for drifting snow. At the three observation sites it was found that the intensity of drifting snow was closely related to reflectivity and wind velocity observed by the Doppler radar. At the Bisyamon site, criteria for intensity of drifting snow were determined by comparing visibility near the surface and Doppler radar sounding aloft. These results are useful for the prediction of the areal distribution of the drift snow intensity based on the Doppler radar monitoring.

In this study, techniques have been proposed to detect the gust front as well as to display the three-dimensional structure of developed cumulus from the Doppler radar observations (Maki and others, 1992a, b). Also, a new
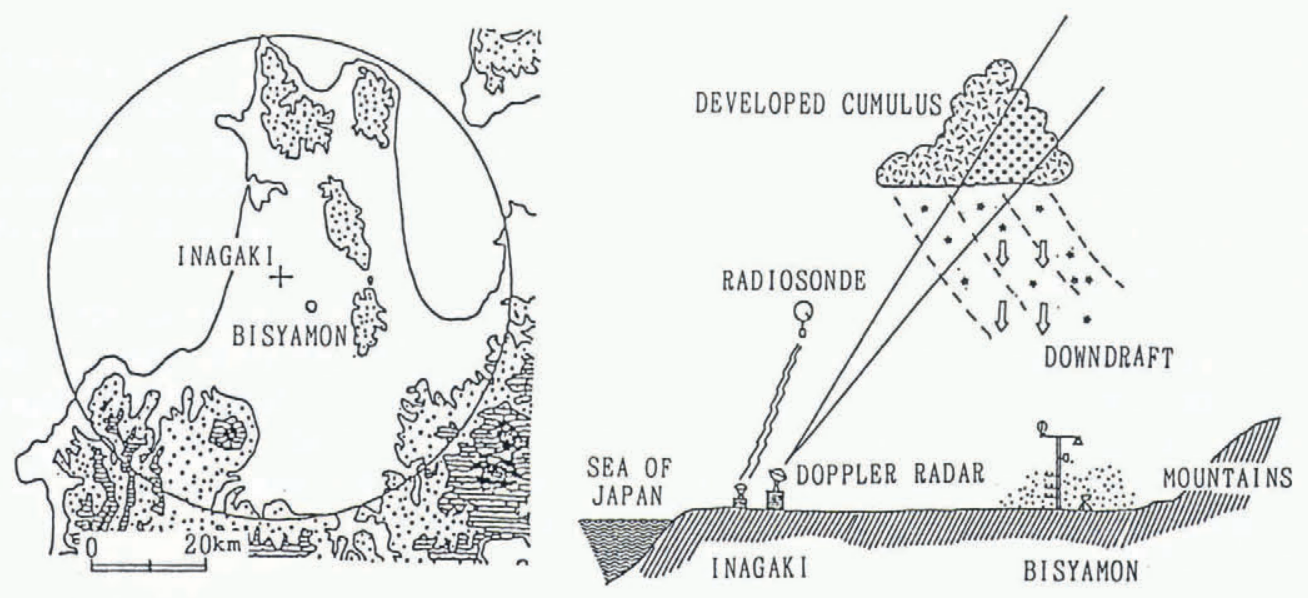

Fig. 8. Topography of Tsugaru Plain and observation sites. Large circle indicates the observation scope of the Doppler radar. +, Doppler radar; $\bigcirc$, Bisyamon observation site. 

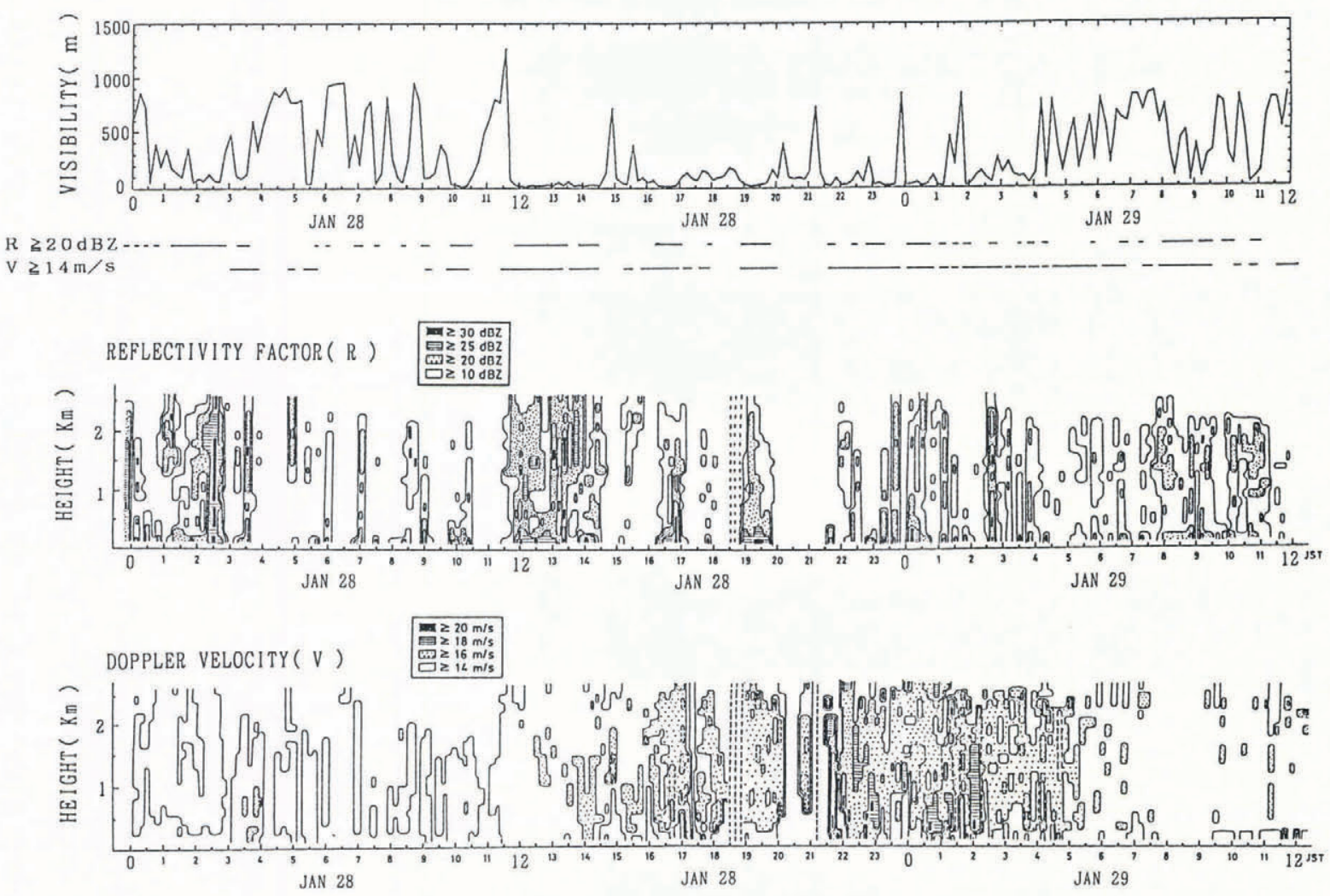

Fig. 9. Comparison between visibility at Bisyamon observation site and observational results of Doppler radar above the site (January 1989). Top, visibility; middle, reflectivity factor of Doppler radar; bottom, Doppler velocity.

SPC system has been developed (Kimura, 1991; Sato and others, 1992) which is convenient, battery-powered and can measure drift snow flux continuously with a high sampling rate of once per second. In 1992, drift-snow flux distribution over a wide area was measured by the improved SPC and cyclone-type drift collectors. Values measured by the two gauges were almost in agreement. An areal warning system, including the prediction of cumulus movement, is now planned on the basis of the present study, using the above-mentioned techniques and instruments.

\section{REFERENCES}

Decker, R. and R. L. Brown. 1983. A turbulent mixture theory for the atmospheric mixture of snow and air. Ann. Glaciol., 4, 37-41.

Fujino, K., S. Kobayashi and G. Wakahama. 1977. Experimental studies of snow accretion. Low Temp. Sci., Ser. $A$ 35, 147-156. [In Japanese with English summary.]

Higashiura, M. 1990. Snow and wind-blowing snow. $\mathcal{F}$. Geogr. (Tokyo), 98(5), 93-108.

Higashiura, M. and A. Sato. 1988. An estimation of the intensity and direction of drifting snow in the Tsugaru Plain. Report of the National Research Center for Disaster Prevention, 41, 387-395.

Kimura, T. 1991. Measurement of drifting snow particles. F. Geogr. (Tokyo), 100(2), 250-263.
Maki, M., T. Yagi and S. Nakai. 1989. The Doppler radar of NRCDP and observation of meso-scale weather systems. Report of the National Research Center for Disaster Prevention, 44, 61-79.

Maki, M., H. Ohkura and T. Mikoshiba. 1992. Applications of 3 dimensional computer graphics to the Doppler radar data processing. Report of the National Research Institute for Earth Science and Disaster Prevention, 49, 53-64.

Maki, M., S. Nakai, T. Yagi and H. Nakamura. 1993. A case study of snowstorms gust and blowing/drifting snow. Ann. Glaciol., 18 (see paper in this volume).

Sato, T. 1990. Sublimation rate of collected blowing snow in a Cyclone type collector. Seppyo. F. Jpn. Soc. Snow Ice, 52(2), 91-98.

Sato, T., T. Kimura, T. Ishimaru and T. Maruyama. 1992. Field test of a new snow-particle counter (SPC) system. Ann. Glaciol., 18 (see paper in this volume).

Shitara, H. 1979. Distribution on snow accumulation observed in a small plain. Sci. Rep. Tohoku Univ., Ser. 7, 29(2), 169-184.

Takeuchi, M. 1978. Snow accretion on traffic-control signs and its prevention. Seppyo. 7. Fpn. Soc. Snow Ice, 40(3), 15-25. [In Japanese with English summary.]

Takeuchi, M. 1980. Vertical profile and horizontal increase of drift-snow transport. F. Glaciol., 26(94), 481-492.

The accuracy of references in the text and in this list is the responsibility of the authors, to whom queries should be addressed. 